\title{
Differential Expression of the p75 Nerve Growth Factor Receptor in Glia and Neurons of the Rat Dorsal Root Ganglia after Peripheral Nerve Transection
}

\author{
Xin-Fu Zhou, ${ }^{1}$ Robert A. Rush, ${ }^{1}$ and Elspeth M. McLachlan ${ }^{2}$ \\ ${ }^{1}$ Departmenl or Physiology and Centre of Neuroscience, Flinders University of South Australia, Bedford Park 5042, \\ Australia, and 2Princes of Wales Medical Research institute, Randwick, NSW 2031, Australia
}

\begin{abstract}
Sympathetic nerve terminals on blood vessels within the dorsal root ganglia sprout after sciatic nerve lesions in the rat. The mechanism underlying this phenomenon is not clear, but might be predicted to involve nerve growth factor or its homologs because these factors are known to trigger collateral sprouting of undamaged sympathetic noradrenergic terminals. We have found that sciatic nerve lesions lead to a decreased expression of neuronal p75, the low-affinity receptor for the neurotrophins, but an increased expression of glial p75 in ipsilateral dorsal root ganglia. Intriguingly, the increased expression of 75 was found primarily in association with glia surrounding large-diameter neurons, which are those associated with the noradrenergic sprouts. A smaller but significant glial response was also found in contralateral ganglia. The glial response in ipsilateral ganglia
\end{abstract}

could be mimicked by ventral, but not dorsal, root transection. The dorsal root lesion-induced glial responses in contralateral ganglia were greater than those induced by ventral root or sciatic nerve lesions. Combined lesions of dorsal root and either ventral root or sciatic nerve did not prevent the glial responses of ipsilateral ganglia, suggesting that a peripheral signal is involved. Colocalization studies indicate that tyrosine hydroxylase-immunoreactive nerve sprouts were associated with p75-immunoreactive glial cells. Thus, increased glial synthesis of p75 might provide an explanation for the abnormal growth of sympathetic fibers in dorsal root ganglia after peripheral nerve injury.

Key words: satellite cells; glial fibrillary acidic protein; sympathetic; nerve injury; glia; sprouting; tyrosine hydroxylase
Patients with peripheral nerve injuries sometimes suffer from chronic pain that can be relieved by blockade of peripheral $\alpha$ adrenoceptors or noradrenaline release (Bonica, 1990; Jänig and Schmidt, 1992). The mechanisms underlying this neuropathic pain are not known, but one factor that may contribute is that sciatic nerve injury triggers sprouting of intact sympathetic nerve fibers from around blood vessels within the dorsal root ganglia (DRG) (McLachlan et al., 1993). These aberrant noradrenergic fibers form varicose baskets primarily around large neurons, and functional evidence implies that synaptic connections are made. In addition, sensory axons within the spinal cord sprout beyond their normal innervation territories after peripheral nerve injury (Richardson and Issa, 1984; Richardson and Verge, 1986; Woolf et al., 1992). The molecular basis for these responses is not clear, but many biochemical and morphological changes in the injured DRG have been documentcd (Rich et al., 1987). For example, sciatic nerve transection leads to downregulation of some neuropeptides but upregulation of others in the afferent neurons (Hökfelt et al., 1994). The loss of neurotrophic factors normally derived from peripheral targets is implicated in these responses because some can be prevented by the simultaneous administration of exogenous growth factors (Verge et al., 1989).

Many studies have focused on the regulation of neurotrophins and

\footnotetext{
Received Dec. 12, 1995; revised Feb. 7, 1996; accepted Feb. 12, 1996.

This work was supported by grants from the National Health and Medical Research Council of Australia to R.A.R., X.F.7., and F.M.M. We are grateful to Dr. E. M. Johnson for providing the 192 antibody.

Correspondence should be addressed to Dr. Xin-Fu Zhou, Department of Physiology and Centre of Neuroscience, Flinders University of South Australia, Bedford Park 5042, Australia.

Copyright (C) 1996 Society for Neuroscience $0270-6474 / 96 / 162901-11 \$ 05.00 / 0$
}

their receptors in Schwann cells (Rush, 1984; Taniuchi et al., 1986; Abrahamson et al., 1987; Heumann et al., 1987; Johnson et al., 1988) and in the corresponding neuronal somata (Sebert and Shooter, 1993) after nerve injury. Sprouting of nerve fibers occurs in a number of situations in which neurotrophic factors have been implicated. Despite the known potent actions of nerve growth factor (NGF), the best characterized neurotrophic factor, on sensory and sympathetic neurons during development in maturity and after neuronal injury, its precise role in nerve sprouting is still a subject of investigation. NGF has a chemotactic ability that results in sensitive nerve fibers following a concentration gradient (Campenot, 1987). Sprouting of NGF-sensitive neurons can be induced in target tissues in vivo by denervation of adjacent regions (Rich et al., 1984), and administration of NGF antiserum prevents this sprouting (Diamond et al., 1992a,b). A possible explanation for these findings is that Schwann cells in the denervated regions upregulate their synthesis of NGF (Abrahamson et al., 1987; Heumann et al., 1987), providing the chemotactic signal. The overexpression of NGF in transgenic animals also leads to sprouting of noradrenergic fibers within effector tissues (Edwards et al., 1989; Federoff et al., 1992) and trigeminal ganglia (Davis et al., 1994).

Johnson and colleagues (Taniuchi et al., 1986; Johnson et al., 1988) have proposed that upregulation of NGF synthesis together with its low-affinity receptor (p75) by Schwann cells surrounding degenerating nerve cell bodies and axons provides a local high concentration of the factor that supports the growth of nerve fibers. Such a mechanism could also account for the intraganglionic sprouting of sympathetic nerves seen after sciatic nerve lesions. We have used immunohistochemistry to examine changes in 75 distribution within the DRG after sciatic nerve lesions. 

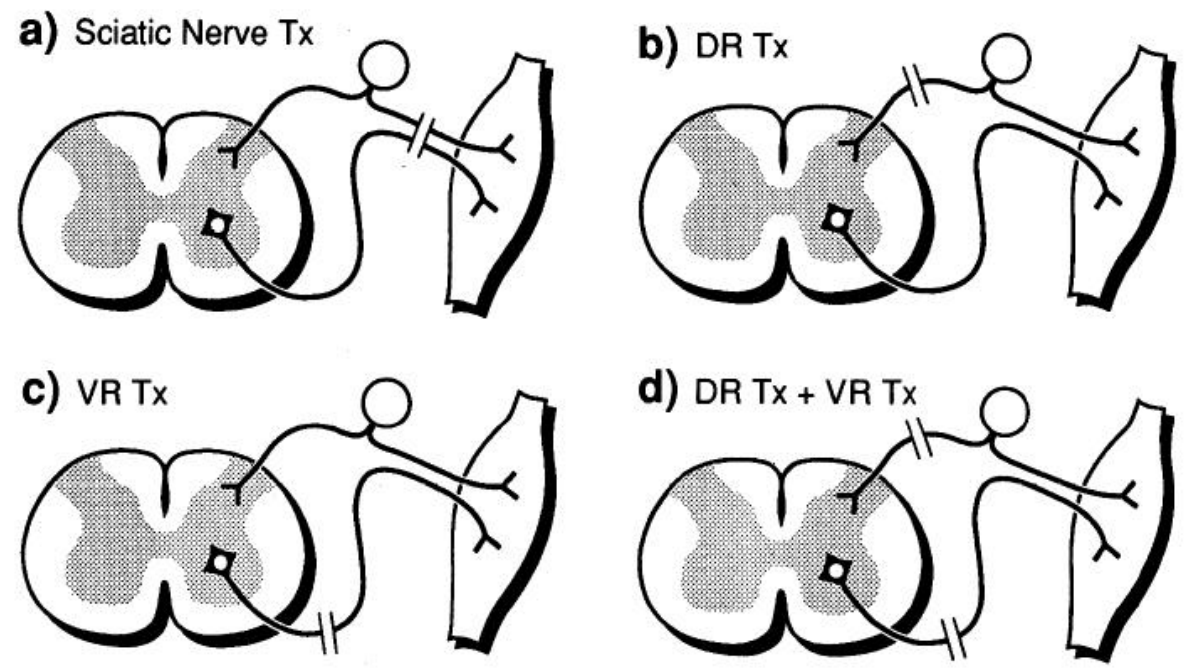

Figure 1. Schematic diagrams showing different nerve lesion paradigms (see Materials and Methods).

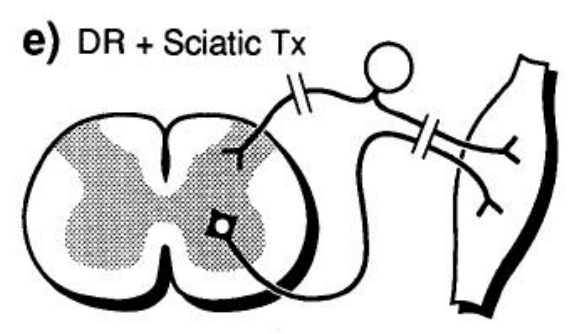

\section{MATERIALS AND METHODS}

Animals. Young adult female Wistar-Kyoto rats were used throughout. All procedures were performed under NH\&MRC guidelines, and approval was provided by the institutional Animal Ethics Committee. Al surgical procedures were performed under inhalational halothane anesthesia except where indicated below. Three or four rats were used for each of the procedures as follows.

Surgery. Nerve lesion paradigms are outlined in the schematic diagrams as shown in Figure 1.

Sciatic nerve transection. The left sciatic nerve was exposed, ligated at the midthigh level, and cut distal to the ligature. Control rats were treated identically except that the sciatic nerve was exposed but not ligated or transected.

Dorsal rhizotomy. Identification of the L5 dorsal root was achieved by removal of the transverse process and dorsal laminae of vertebra to expose the DRG and associated dorsal root. Fine scissors were used to section the dorsal root $2 \mathrm{~mm}$ from the ganglion, taking care to avoid damage to the ventral root.

Ventral root transection. The L5 DRG ventral root was exposed as described above and transected $2 \mathrm{~mm}$ from the ganglion. The ventral root was sectioned after approaching from the lateral aspect to avoid damage to the dorsal root.

Combined ventral and dorsal root section. Both ventral and dorsal roots (L5) were transected after their identification by the procedure described above.

Combined sciatic nerve and dorsal root section. In three rats, both the sciatic nerve and the dorsal root were sectioned as described above.

Immunohistochemistry. Rats were allowed to survive for $1,2,4$, and 8 weeks after the sciatic nerve lesion and 2 weeks after the other lesions. Pentobarbital $(80 \mathrm{mg} / \mathrm{kg}$, i.p.) was used to anesthetize the rats before perfusion through the heart with $100 \mathrm{ml}$ of $0.1 \mathrm{M}$ phosphate

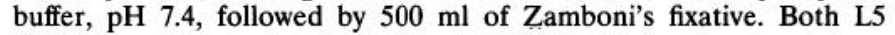
DRGs were dissected and post-fixed in Zamboni's fixative overnight at

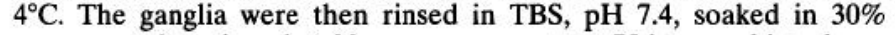
sucrose, and sectioned at $30 \mu \mathrm{m}$ on a cryostat. p75 immunohistochemistry was performed as described previously (Zhou et al., 1993). Briefly, sections were washed and blocked before overnight incubation in primary monoclonal antibody 192 (a gift from Dr. Eugene Johnson) at $2 \mu \mathrm{g} / \mathrm{ml}$. The sections were incubated with AMCA-conjugated donkey antibody to mouse IgG (Jackson Laboratories, Bar Harbor, ME) for 2 $\mathrm{hr}$ at a dilution of 1:50. In some cases, the sections were incubated with horseradish peroxidase-conjugated secondary antibodies in place of the fluorescent antibody and developed in diaminobenzidine (DAB) solution enhanced by nickel sulfate as described elsewhere (Zhou et al., 1993).

For colocalization of p75 with either glial fibrillary acidic protein (GFAP) or tyrosine hydroxylase (TH), DRGs from animals 1 or 2 weeks after sciatic nerve transection were removed, sectioned, and incubated in both mouse monoclonal $192 \mathrm{IgG}(2 \mu \mathrm{g} / \mathrm{ml})$ and rabbit polyclonal antibodies to GFAP (Dako, Carpenteria, CA; 1:1000) or TH (Pel-Freez Biologicals, Rogers, AR; 1:200). Secondary donkey antibodies (Jackson) to mouse IgG (AMCA-labeled) and rabbit IgG (FITC-labeled) were both diluted at 1:50 and applied to sections for $2 \mathrm{hr}$.

The sections were mounted in buffered glycerol and observed under a fluorescence microscope. DAB sections were mounted in xylene-based medium and observed using bright-field illumination. The number of p75-immunoreactive (-ir) neurons and neurons surrounded by p75-ir glia and nerve fibers (ring structures) were counted in five randomly selected sections from three to four rats in each group. The same sections were then counter-stained with thionin, and the total number of neurons was counted.

\section{RESULTS}

\section{Controls}

In DRGs of normal rats, $\sim 60 \%$ of all neurons were immunoreactive for p75 (see Figs. 2.1, 3). The staining was present in neurons with a wide range of soma sizes, appearing as a granular stain localized to the soma cytoplasm and some nerve fibers (Fig. 2.1). Occasionally, p75-ir was present in glia and nerve fibers surrounding neuronal somata in the shape of ring structures. These ring structures were almost always associated with large-diameter neurons, consistent with previous reports by others and this laboratory (Verge et al., 1989; Zhou et al., 1993).

\section{Effects of sciatic nerve lesions Ipsilateral DRGs}

After sciatic nerve lesions, p75-ir was changed as judged by a number of criteria. 

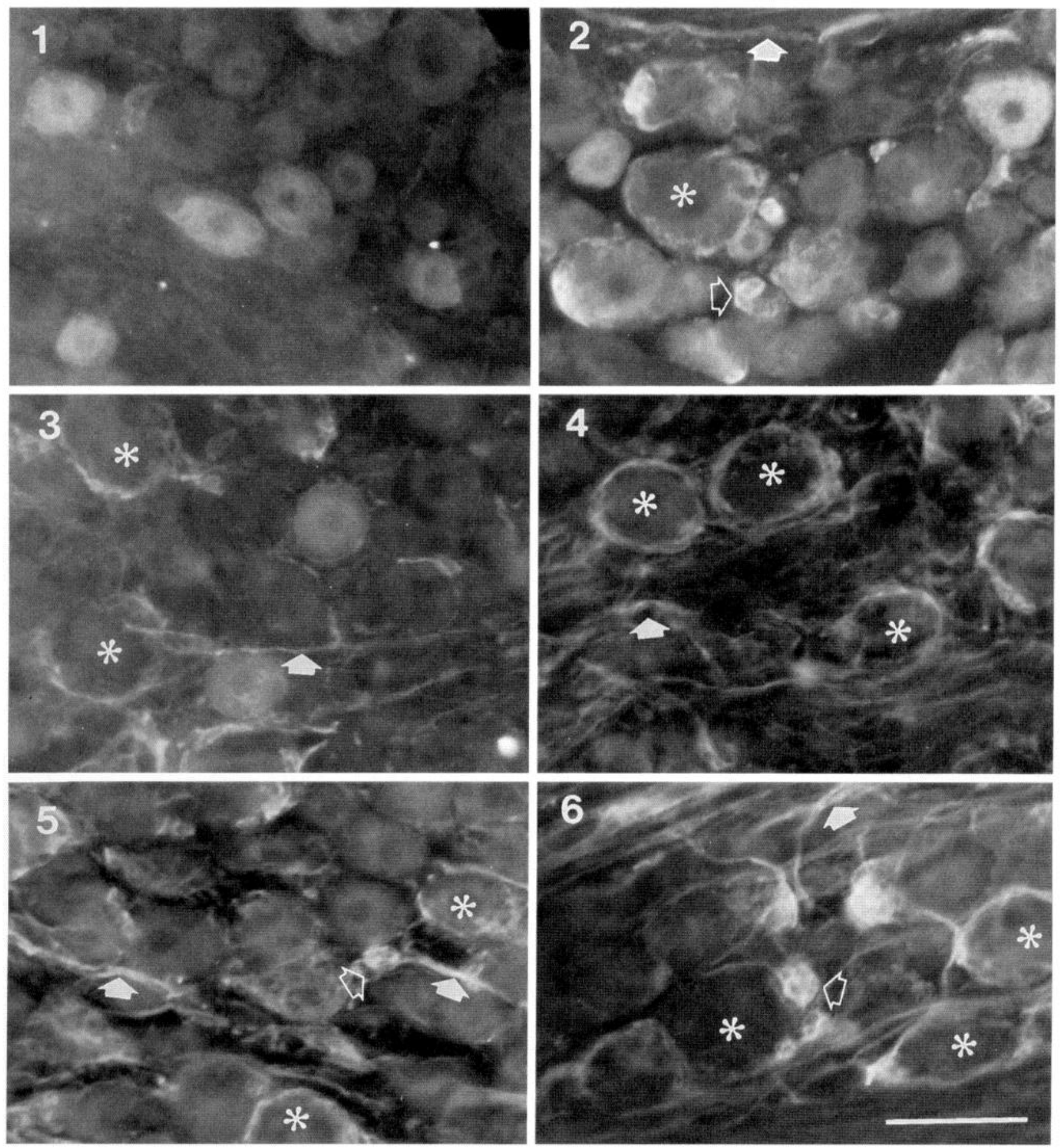

Figure 2. Effects of sciatic nerve transection on the expression of p75-ir within L5 DRG. 1, A section from sham-operated rats showing subpopulations of large and small p75-ir neurons. 2, A section from contralateral DRG 8 weeks after sciatic nerve transection showing increased expression of p75-ir in fibers and glia surrounding some large neurons. 3-6, One, two, four, and eight weeks, respectively, after ipsilateral sciatic nerve transection showing decreased expression of p75-ir in neurons and increased expression in nerve bundles and glia. Asterisks indicate a neuron with surrounding ring of immunoreactivity; open arrows indicate clusters of p75-ir glial cells; filled arrows indicate p75-ir nerve bundles. Scale bar, $50 \mu \mathrm{m}$.

(1) One week after injury, the intensity of staining and the number of immunoreactive neuronal cell bodies were significantly reduced (Fig. 2.3), resulting in fewer positive cells $(26 \%)$ compared with $51 \%$ in the intact DRG (Fig. 3). These changes became more marked with time. Only $13 \%$ of all neurons were p75-ir by 8 weeks postlesion. In contrast, there were no significant changes from control in the percentages of positive neurons in the contralateral ganglia (Fig. 2.2).

(2) The number of immunoreactive nerve bundles within the ipsilateral DRG increased significantly 1 week after operation and remained elevated for 8 weeks (see filled arrows in Fig. 2.5, 2.6). There was also a slight increase in the same immunoreactive nerve 


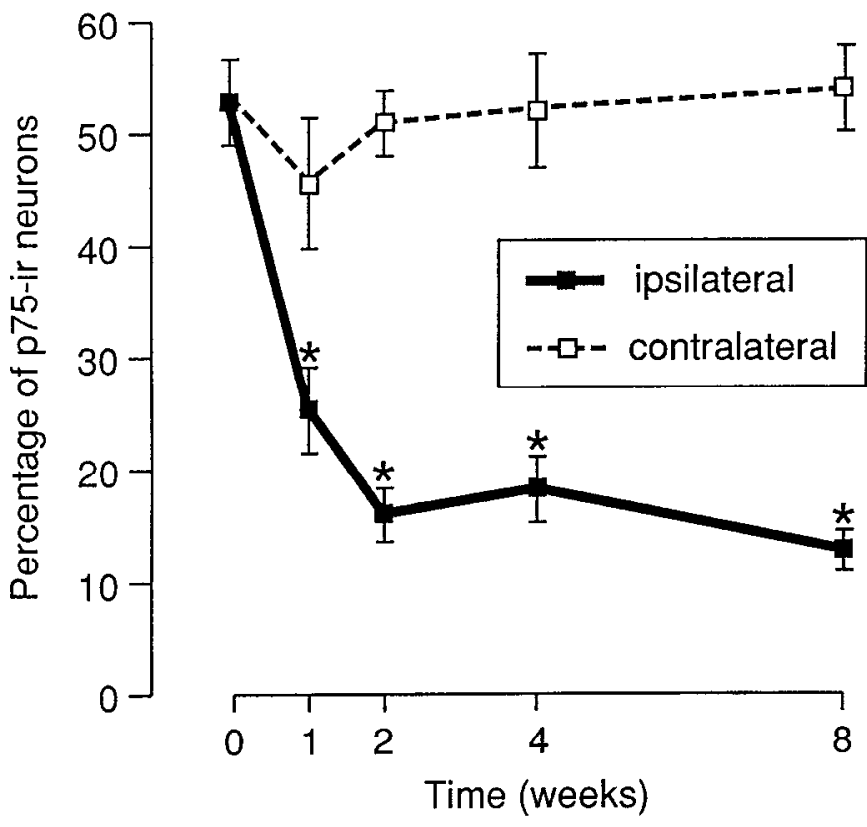

Figure 3. Effect of sciatic nerve transection on the percentage of p75-ir neurons in L5 DRG. The numbers of p75-ir neurons were counted as described in Materials and Methods. The data are plotted as mean \pm SEM $(n=4)$. The percentage of p75-ir neurons was significantly reduced after sciatic nerve transection (asterisks indicate $p<0.05$ compared with control).

bundles in the contralateral DRG at all times examined (see filled arrow in Fig. 2.2).

(3) After sciatic lesions, p75-ir increased strongly in glia around many primary afferent neurons. This immunoreactivity was in the form of ring-shaped structures, most of which encircled largediameter neuron somata (see asterisk in Fig. 2). We have observed that clusters of glial cells aggregate around one pole of large sensory neurons and express p75-ir. These p75-ir ring structures appeared similar to the arrangement of catecholamine-containing fibers described in a previous study (McLachlan et al., 1993). Quantitative analysis showed that the percentage of neurons surrounded by these ring structures increased dramatically from $0.5 \%$ in control ganglia to $35 \% 1$ week after nerve lesion and to $39 \%$ at 8 weeks postlesion (Fig. 4).

(4) Some glia that were in clusters but not surrounding neurons were strongly immunoreactive for $\mathrm{p} 75$ after peripheral nerve lesions (see open arrow in 2.6). These glia were usually located between large neurons and also occurred in the contralateral DRGs after sciatic nerve lesion (see open arrow in Fig. 2.2); they were only rarely seen in control DRGs. Cresyl violet staining also showed a significant increase in the number of glial cells surrounding lesioned sensory neurons (data not shown).

\section{Contralateral DRGs}

In the contralateral DRGs, similar changes of $p 75$ expression were seen in both nerve bundles and glia, but not in neuronal somata. The number of immunoreactive ring structures was increased significantly at 2 weeks $(p<0.05)$ and 8 weeks $(p<0.05)$ after sciatic nerve injury, although their number was always far less than that seen in ipsilateral ganglia (Fig. 4). In contrast to the ipsilateral DRGs, both the number of neuron somata immunoreactive for p75 and the intensity of the stain within each neuron were unaffected by the sciatic nerve lesion.

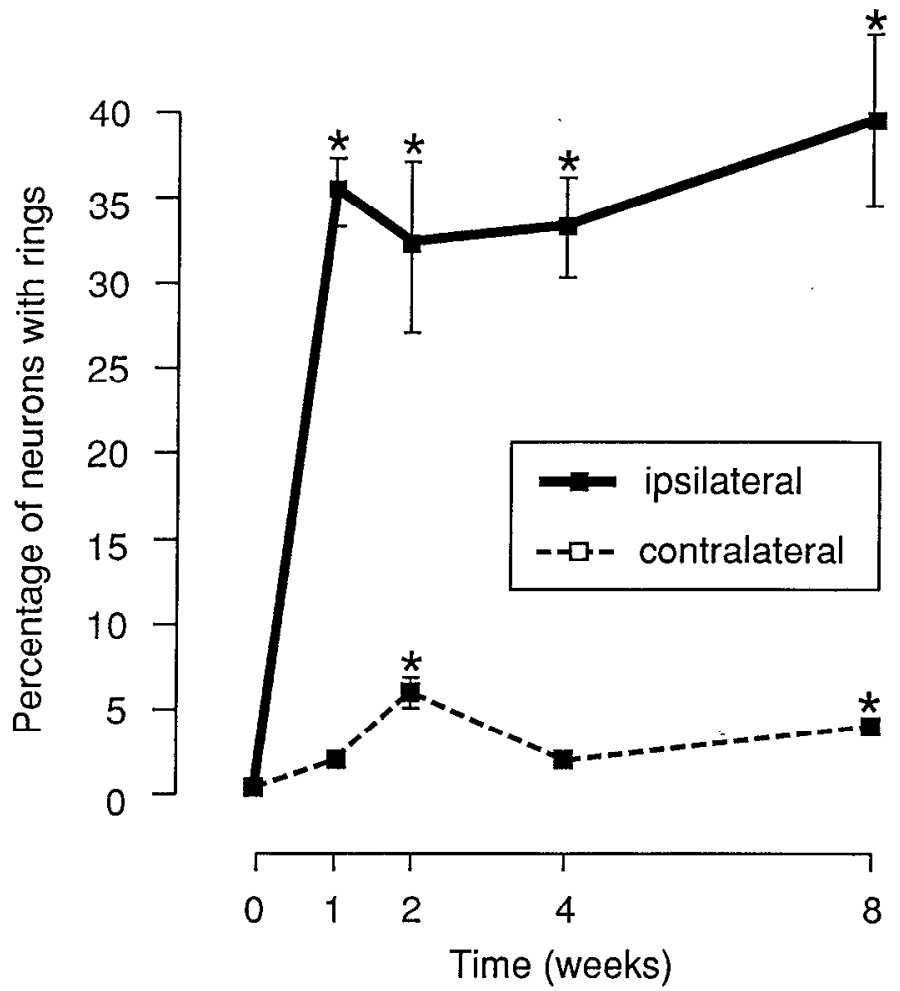

Figure 4. Effect of sciatic nerve transection on the number of p75-ir ring structures surrounding neurons. The neurons surrounded by $\mathrm{p} 75$-ir glia or nerve fibers were counted as described in Materials and Methods and are plotted as mean \pm SEM $(n=4)$. The percentage of neurons with ring structures in ipsi- and contralateral DRG after sciatic nerve lesion was significantly increased with postlesion time (asterisks indicate $p<0.05$ compared with control).

In three rats 2 weeks after sciatic nerve lesions, cervical DRGs (C6) were also examined for p75 expression. These ganglia appeared identical to corresponding ones from control unoperated rats (data not shown).

\section{Colocalization of p75 with GFAP}

To test whether the p75-ir was associated with glia, colocalization of p75-ir with the glial cell marker GFAP-ir was performed. After sciatic nerve lesions, a significant increase in GFAP-ir glial cells was seen, particularly surrounding large neurons and in some nerve bundles. As shown in Figure 5, the p75-ir present in ring structures surrounding large neurons and some nerve bundles was colocalized with GFAP-ir in both the ipsilateral (compare Fig. 5.1 with 5.2) and contralateral DRG (compare Fig. 5.3 with 5.4), indicating that a proportion of the p75-ir was localized to both satellite cells (ring structures) and Schwann cells (in nerve bundles). No GFAP-ir was associated with or without $\mathrm{p} 75$-ir in neuron somata. GFAP-ir and p75-ir were also colocalized in glial clusters that were not associated with neurons (compare Fig. 5.5 with 5.6). However, some GFAP-ir glia around small-diameter primary afferent neurons were not immunoreactive for $\mathrm{p} 75$.

\section{Effects of ventral root transection on p75 expression}

As expected from several previous studies (Koliatsos et al., 1991; Greeson et al., 1992; Rende et al., 1993), ventral root transection significantly increased the expression of $\mathrm{p} 75$ within the ventral roots and peripheral nerves distal to the lesion site. 

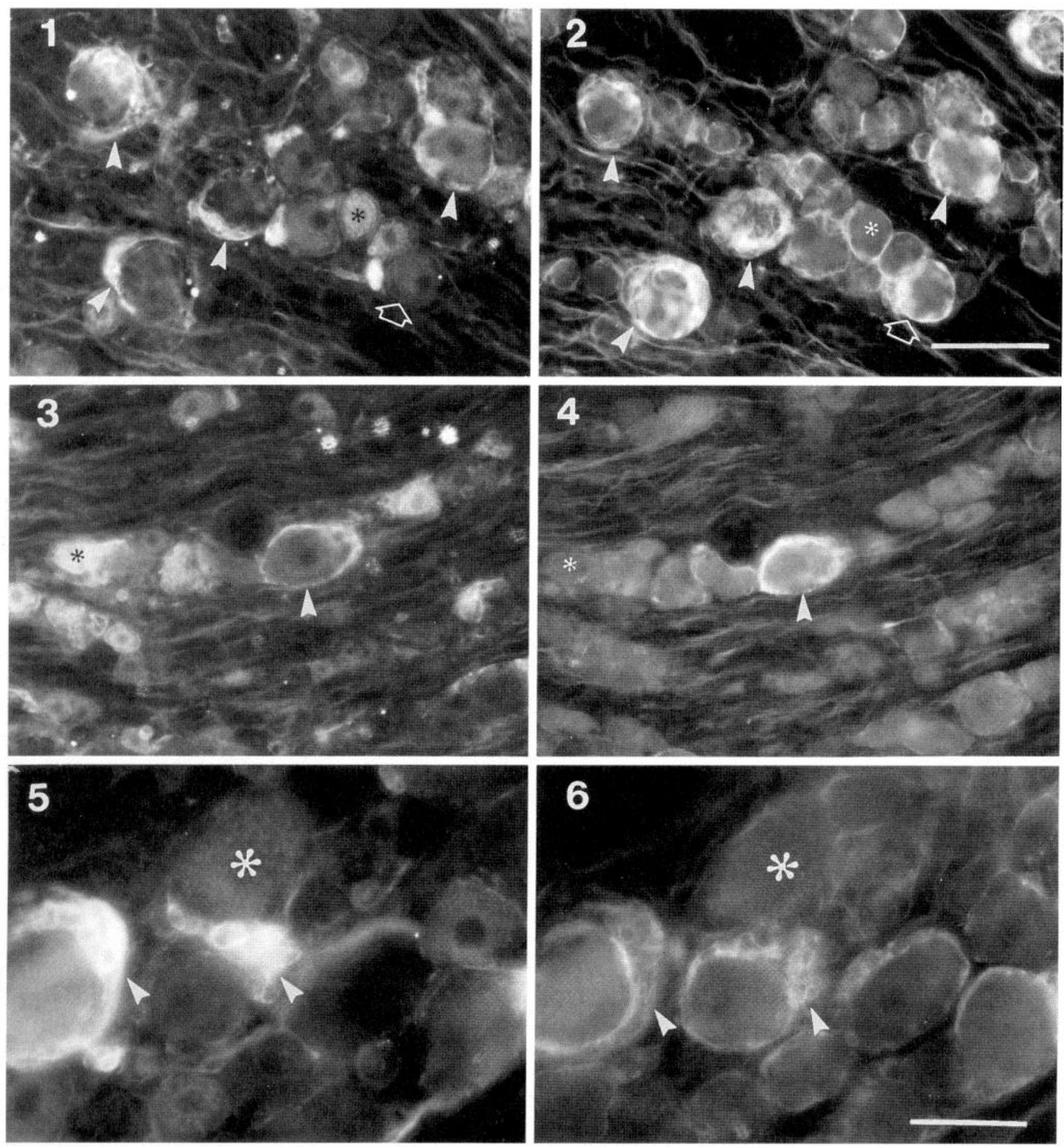

Figure 5. Colocalization of p75-ir with GFAP-ir in the ipsilateral (panels 1,2,5,6) and contralateral (panels 3, 4) L5 DRG after sciatic nerve transection. Panels 1,3, and 5 are sections stained with mouse antibodies to p75 followed by AMCA-conjugated secondary antibodies, and panels 2, 4, and 6 are the same sections stained with rabbit antibodies to GFAP followed by FITC-conjugated secondary antibodies. Asterisks indicate neurons immunoreactive for p75 but negative for GFAP-ir; arrowheads in 1-4 indicate large neurons with p75-ir ring structures that were also immunoreactive for GFAP; arrowheads in 5 and 6 indicate clusters of glial cells that are both p75-ir and GFAP-ir; open arrows in 1 and 2 indicate a small neuron without p75-ir ring structure but with GFAP-ir. Scale bars: $1-4$ (shown in 2), $100 \mu \mathrm{m} ; 5,6$ (shown in 6 ), $50 \mu \mathrm{m}$.

No p75-ir could be detected within the dorsal roots. Because dorsal root damage is known to result in upregulation of p75-ir within glia of the dorsal root nerve bundles (Henry et al., 1993) (also see below), the absence of p75-ir in the dorsal root served as a sensitive indicator of the absence of dorsal root damage after ventral root transection. Surprisingly, within the corresponding DRGs, p75-ir glia and nerve fibers also increased, so that by 2 weeks after ventral root transection many immunoreactive ring structures were clearly visible (Fig. 6.2, Table 1). The number of ring structures $(28.9 \pm 4.0 \%)$ was comparable with the number $(33.0 \pm 5.1 \%)$ seen after sciatic nerve transection (Fig. 7). However, unlike after sciatic nerve lesions, the p75-ir within primary afferent neuron somata was only slightly reduced. In the contralateral DRGs, ring structures were also 

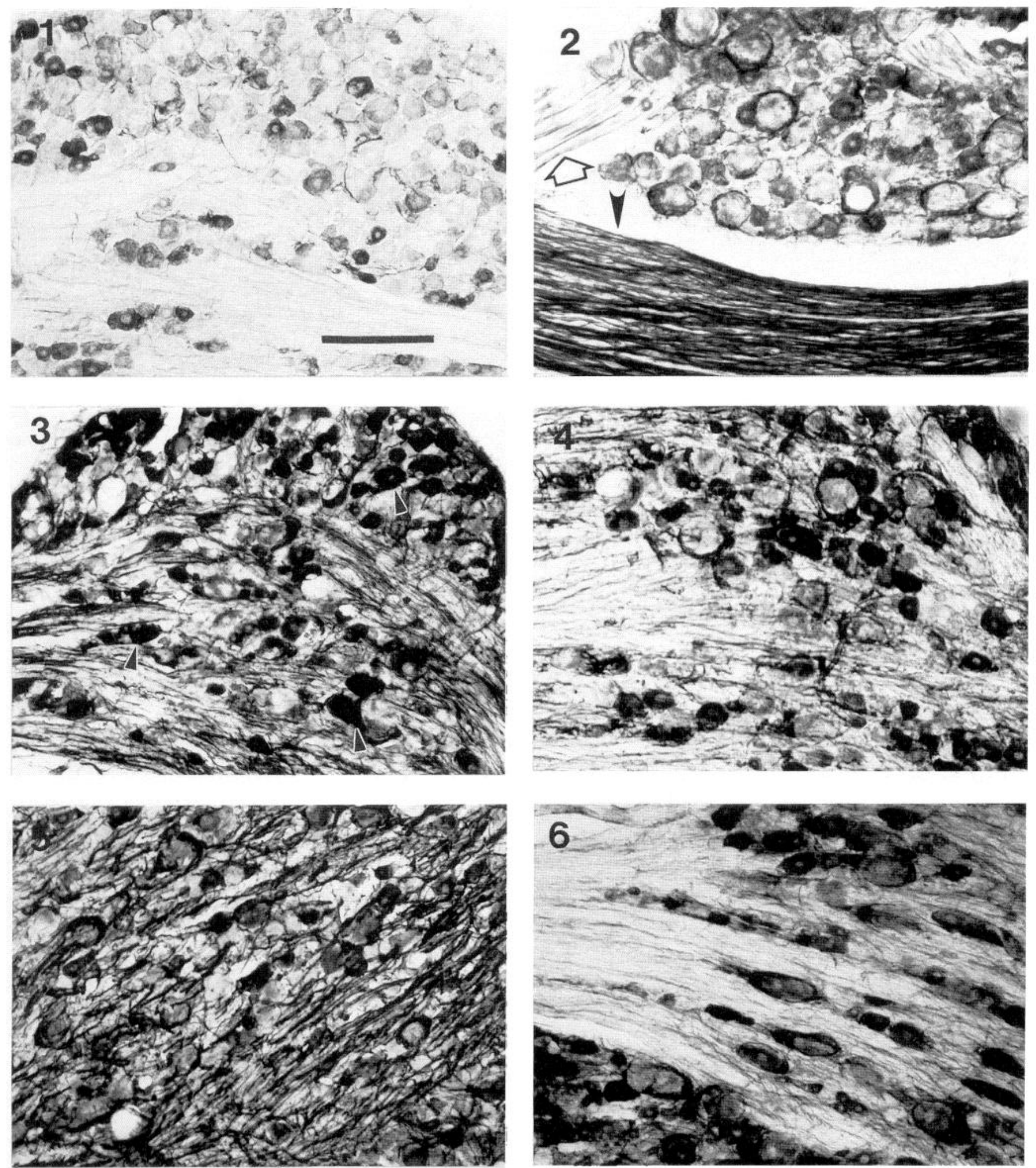

Figure 6. Effects of ventral root, dorsal root, and combined dorsal and ventral root transections on p75-ir in L5 DRGs. 1, A micrograph showing normal expression of p75 in the sham-operated DRGs. 2, A micrograph showing ring structures around large neurons from an animal with an L5 ventral root transection one week earlier. An open arrow indicates intact dorsal root, and an arrowhead indicates lesioned ventral root. 3, 4, Micrographs of the respective ipsi- and contralateral DRG from an animal with a transection of dorsal root of the L5 spinal ganglion one week earlier. Arrowheads in 3 indicate intensely labeled DRG neurons. 5, 6, Micrographs of respective ipsi- and contralateral DRG from an animal with combined lesion of dorsal and ventral root of the L5 spinal ganglion 1 week earlier. Scale bar, $200 \mu \mathrm{m}$.

seen but in fewer numbers $(6.3 \pm 0.6 \%, p<0.01$ compared with ipsilateral DRG). No significant change in p75 expression was seen in two animals subjected to sham operations.
Effects of dorsal root transection on p75 expression

In contrast to the sciatic nerve lesions, which triggered a reduction of p75-ir within ipsilateral ganglionic neuron somata, dorsal root 
Table 1. Summary of effects of different nerve lesions on expression of p75 in neurons, glial ring structures, and nerve bundles in the ipsilateral and contralateral DRGs

\begin{tabular}{|c|c|c|c|c|c|c|}
\hline \multirow[b]{2}{*}{ Lesion } & \multicolumn{3}{|c|}{ Ipsilateral DRG } & \multicolumn{3}{|c|}{ Contralateral DRG } \\
\hline & $N$ & GR & NB & $\mathrm{N}$ & GR & NB \\
\hline Sci. n. & $\downarrow$ & ++++ & ++ & - & ++ & + \\
\hline DR & $\uparrow$ & $+1-$ & ++++ & - & +++ & + \\
\hline VR & - & ++++ & + & - & ++ & + \\
\hline $\mathrm{DR}+\mathrm{VR}$ & $\uparrow$ & +++ & +++ & - & +++ & + \\
\hline $\mathrm{DR}+$ Sci. $\mathrm{n}$. & $\downarrow$ & ++++ & ++++ & - & ++ & + \\
\hline
\end{tabular}

The lesion paradigms are schematically shown in Figure 1. Sci. n., sciatic nerve section; VR, ventral root section; $D R$, dorsal root section; $N$, neuron; $G R$, glial ring structures; NB, nerve bundles. Changes were scored as follows: - , no change; $+/-$, minimal change; ++++ , maximal change; ++ and $1++$, intcrmediatc changes. Up arrow and down arrow indicate increased and decreased p75-ir in neurons.

lesions induced increases in both the number and the intensity of staining of p75-ir neurons (Fig. 6.3, Table 1). In addition, p75-ir was also increased in the intraganglionic nerve bundles compared with control rats (see Fig. 6.1, Table 1). However, in contrast to the sciatic nerve lesions, the dorsal root lesion triggered a slight significant increase in p75-ir in ganglionic satellite cells. Only 2.2 $\pm 0.7 \%$ of neurons were surrounded with p 75 -ir glia. In contralateral ganglia, $17.9 \pm 1.6 \%$ of $\mathrm{p} 75$-ir ring structures were observed, a response greater than that after sciatic nerve lesions $(p<0.05$; Figs. 6.4, 7, Table 1).

\section{Effects of combined dorsal and ventral root transections}

To determine whether the signals upregulating p75-ir in satellite cells after ventral root lesions are mediated through the spinal cord and dorsal roots, both ventral and dorsal roots were cut in another group of animals. As shown in Figures 6.5 and 7 and Table 1 , the combined lesion did not significantly reduce the number of p75-ir ring structures in the ipsilateral DRG (combined, $27.8 \pm 1.9 \%$; ventral root only, $28.9 \pm 4.0 \%$ ), suggesting that the signals inducing these after ventral lesion did not derive from the spinal cord. The p75-ir within primary afferent neurons and nerve bundles, like that after dorsal root lesions only, was also increased markedly by the combined lesion. In comparison with the ventral root or sciatic nerve lesions, the number of ring structures in the contralateral DRGs was significantly increased $(22.6 \pm 2.0$ vs $6.5 \pm 1.2 \% ; p$ $<0.01)$ but was comparable with the response to dorsal root lesion only $(17.9 \pm 1.6 \%)$. The pattern of $\mathrm{p} 75$-ir expressed in the contralateral DRGs (Fig. 6.6) was similar to that seen after ventral or dorsal root lesions only (Table 1).

\section{Effect of combined sciatic nerve and dorsal root lesion}

To determine whether the signals upregulating $\mathrm{p} 75$-ir in satellite cells after sciatic nerve lesion are derived from the spinal cord through the dorsal root, sciatic nerve section was combined with dorsal root section. As shown in Figure 7 and Table 1, the number of ring structures after the combined lesions was comparable with sciatic nerve lesion only $(33.5 \pm 4.4$ vs $32.0 \pm 5.1)$. Similar to changes observed after sciatic nerve lesion only, but in contrast to dorsal root lesion only, $\mathrm{p} 75$-ir in sensory neurons was also reduced by the combined lesion (data not shown). In addition, $\mathrm{p} 75$-ir in the nerve bundles within the DRGs was also increased. The number of ring structures in the contralateral DRGs was $10.2 \pm 1.2 \%$, more than the sciatic nerve lesion only $(p<0.05)$, but not as high as combined lesions of dorsal and ventral roots $(p<0.05)$ or dorsal root only $(p<0.05)$.

\section{Colocalization of p75 glial ring structures with $\mathrm{TH}-\mathrm{ir}$ nerve sprouts}

To determine the relationship between glial p75 ring structures and catecholaminergic nerve axons, double labeling of p75 and TH was performed. One week after sciatic nerve lesion, TH-ir fibers were identified within the ipsilateral L4 and L5 DRGs. These fibers were mostly found around large sensory neurons and associated satellite cells (compare Fig. 8.1 with 8.2) or Schwann cells in the nerve bundles (compare Fig. 8.3 with 8.4). Some of these fibers could be traced back to nerve fibers surrounding small blood vessels. TH-ir axons ran over or between p75-ir satellite cells (Fig. 8.1, arrowheads). Because of strong glial p75-ir, it was difficult to determine whether or not $\mathrm{TH}$-ir fibers associated with these glia were also p75-ir. However, where TH-ir fibers were not associated with p75-ir glial cells, they were always themselves p75-ir (compare Fig. 8.5 with 8.6).

\section{DISCUSSION}

The present study has revealed differential expression of p75 in neurons and glia in DRGs after sciatic nerve injury. A reduction in p75-ir in cell bodies, consistent with previous histological and biochemical demonstration of mRNA ${ }^{p 75}$ (Sebert and Shooler, 1993), contrasted with an increase identified in glia, primarily those surrounding large-diameter sensory neurons. There was also upregulation of p75 in equivalent contralateral ganglia. TH-ir axons were associated with $\mathrm{p} 75$-ir glia, suggesting a relationship between the sprouting of noradrenergic axons and the glial response.

p75 expression within DRG neurons appears to be regulated by signals from peripheral tissues, because only lesions that damaged

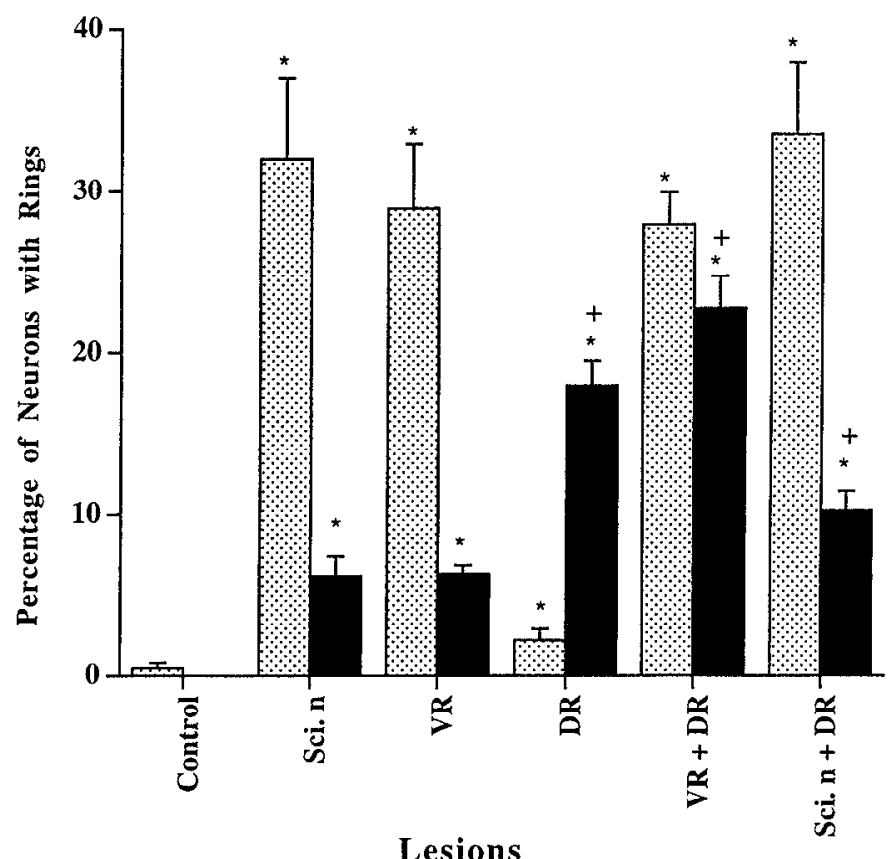

Figure 7. Effects of nerve lesions on the numbers of $\mathrm{p} 75$-ir ring structures in the DRGs ipsi- and contralateral to the lesions. The surgical procedures were as described in Materials and Methods. Shaded bars, Ipsilateral DRGs; filled bars, contralateral DRGs. Sci. $n$, Sciatic nerve division; $V R$, ventral root section; $D R$, dorsal root section. ANOVA: $F=31.7$, $p<0.01 ;{ }^{*} p<0.01$ compared with control; ${ }^{+} p<0.05$ compared with DRG contralateral to sciatic nerve division alone (filled bar). 

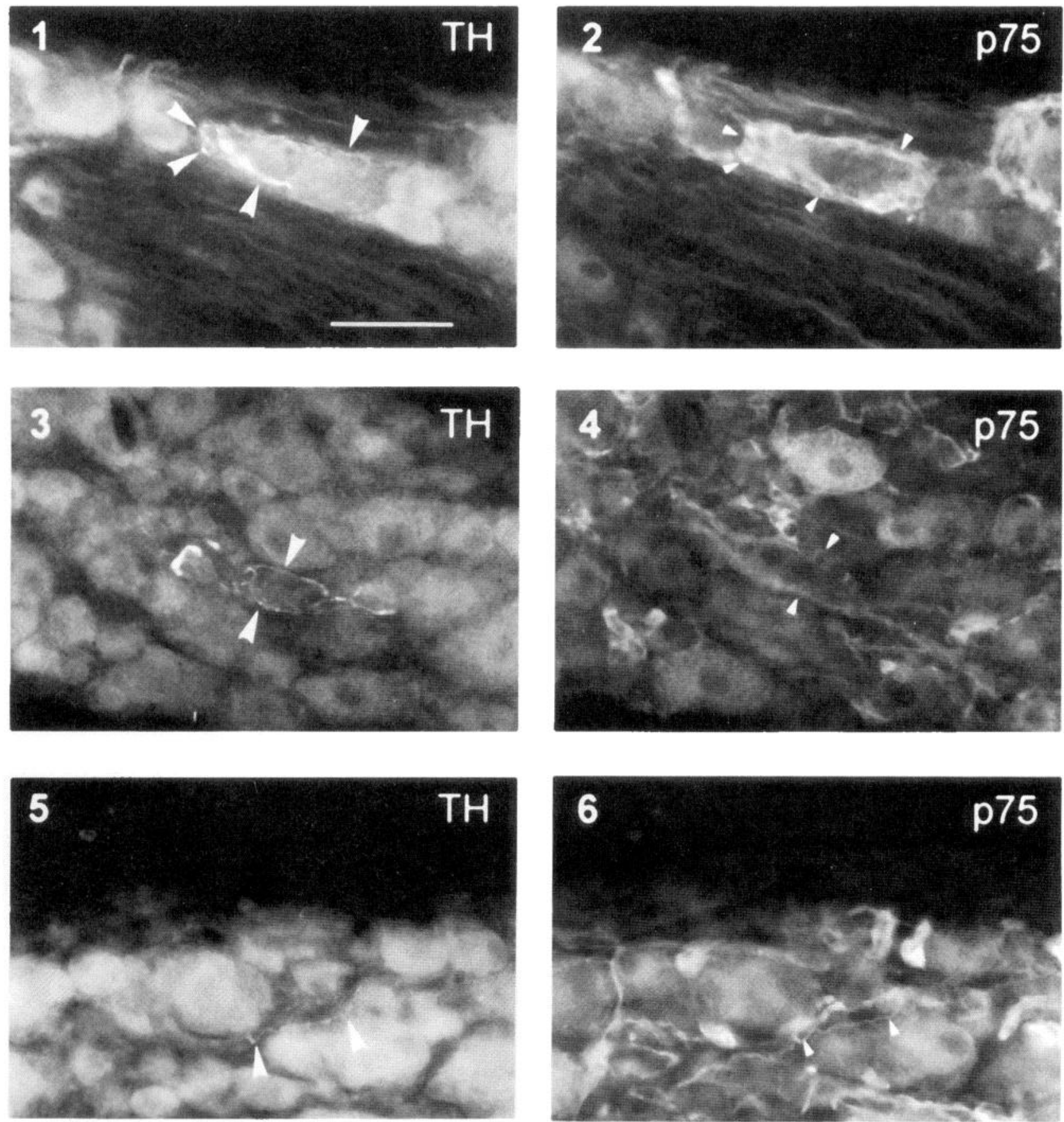

Figure 8. Colocalization of TH-ir axons with p75-ir glia and nerve fibers in ipsilateral DRG 1 week after sciatic nerve lesion. Pairs of micrographs (1,2; $3,4 ; 5,6)$ are each of the same section using different filters. Large arrowheads in 1,3 , and 5 indicate TH-ir nerve fibers; small arrowheads in 2 indicate p75-ir satellite cells associated with a large neuron surrounded by TH-ir nerve terminals (1); arrowheads in 4 indicate nerve bundles immunoreactive for p75 in the same site as TH-ir fibers (3); arrowheads in 6 indicate p75-ir colocalized with a TH-ir nerve fiber. Scale bar (shown in $I$ ), $100 \mu \mathrm{m}$. In $I, 3$, and 5, which show TH-ir fibers, significant autofluorescence of sensory neurons was observed with the filter for FITC.

peripheral sensory axons led to the loss of its expression. The regulating signals are not known, but one seems likely to be NGF. NGF increases p75 mRNA in cultured primary afferent neurons in vitro (Lindsay et al., 1990) and partially prevents the loss of p75 induced by axotomy in vivo (Verge et al., 1992). However, NGF may not be the only factor involved because removal of endogenous NGF by its antibodies in vivo results in complete depletion of p75 in sympathetic neurons but has no effect on its expression in sensory neurons (Zhou and Rush, 1996).
In contrast, p75 expression in glia after lesions of either the sciatic nerve or the ventral (but not dorsal) roots suggests that its upregulation is associated with damage to motor nerve fibers. The glial cells that respond are mainly those associated with largediameter primary afferent neurons with low-threshold mechanosensitive endings in the periphery. This increased expression of glial p75 has not been reported previously either for mRNA or by protein analysis of DRGs.

p75 expression in nerve bundles in the DRGs was increased 
in response to all lesion paradigms, particularly dorsal rhizotomy. The dramatic upregulation after dorsal root lesion resembled that in the distal stump after sciatic nerve lesions in which p75 is also involved in the Schwann cells (Taniuchi et al., 1986). Because the p75-ir in DRGs also express GFAP, Schwann cells must be involved. Double labeling reveals that, in addition, sympathetic fibers expressed $\mathrm{p} 75$ and may also be present in the nerve bundles.

The p75-ir glial rings occurred much more frequently than the rings of noradrenergic terminals observed after similar sciatic lesions (McLachlan et al., 1993). From their frequency (around nearly $40 \%$ of neurons), it might seem that the p75-ir rings occurred only around axotomized cells as $\sim 50 \%$ of L5 DRG cells project in the lesioned sciatic nerve (Devor et al., 1985). However, because p 75-ir rings were primarily associated with large somata, they must have involved most of the large cells in the ganglion, i.e., including those that had not been axotomized. If so, the formation of sympathetic rings must be restricted to a subpopulation of DRG neurons, perhaps those located relatively closer to the arterial vessels from which the sprouts arise. It is not clear whether the sprouts only surround axotomized cells.

Because the number of GFAP-ir glia within the DRG after lesions was substantially increased, the colocalization of $\mathrm{p} 75$-ir with GFAP-ir seen in the present study suggests that upregulation of the receptor is associated with glial proliferation. The signal regulating this response is not known, but it is probably not attributable to factors secreted by invading macrophages (Lu and Richardson, 1991) because the response is not random, but is primarily localized to satellite cells surrounding large neurons. The increases in GFAP-ir and p75-ir after nerve injury may be the result either of proliferation (Lu and Richardson, 1991) or of upregulation of these molecules in existing satellite cells. GFAP-ir and p75-ir may only be present in newly generated glial cells in the affected DRG. The presence of few GFAP-ir glial cells in intact DRG supports this idea. This hypothesis could be tested by combining p75 or GFAP immunohistochemistry with DNAlabeling techniques.

The lack of a widespread increase in $\mathrm{p} 75$ expression, both in the cervical DRGs examined here and in ipsilateral trigeminal ganglia after retrogasserian rhizotomy (Henry et al., 1993), rules out a hormonal mechanism. However, local autacoid production cannot be excluded, because it is known that both local autacoid (Dropp and Sodetz, 1971) and neuronal (Schwyn, 1967) signals regulate glial cell proliferation in autonomic and dorsal root ganglia. The release of hormonal factors from degenerating nerve fibers or local inflammatory cells may be responsible ( $\mathrm{Lu}$ and Richardson, 1991; Pubols and Fogleson, 1988). This is supported by evidence indicating that ventral rhizotomy or local inflammation enhances the sprouting of intact primary afferent neurons (Rich and Johnson, 1985; Lu and Richardson, 1991). However, the local reaction to dorsal rhizotomy did not produce much satellite cell p75 response in the ipsilateral DRG (Fig. 6) (see also Henry et al., 1993).

The appearance of glial rings in the contralateral DRG again parallels the contralateral sprouting of sympathetic axons (McLachlan et al., 1993). The formation of these rings was enhanced when dorsal roots, rather than sciatic nerves, had been lesioned. This might result from the larger number of primary afferent axons of damaged DRG cells present in the cord. A number of morphological, biochemical, and functional changes have been described contralaterally after peripheral nerve injury (Rotshenker, 1988; Kolston et al., 1991) or unilateral adjuvant- induced arthritis (Donaldson et al., 1995). A transneuronal mechanism in the dorsal horns via crossed collaterals of damaged afferent axons seems to be a possible explanation. Capsaicin treatment blocked the contralateral changes in the arthritis model (Donaldson et al., 1995), implicating the involvement of smalldiameter nociceptive axons.

\section{Possible peripheral mechanisms}

Because selective lesions of motor nerve fibers in L5 ventral root mimicked the response to sciatic transection in producing $\mathrm{p} 75$-ir rings, direct trauma to primary afferent neurons is not mandatory for this response. Further, lesions of dorsal roots alone had little effect on the appearance of the rings and also failed to block the effects of ventral rhizotomy, indicating that the effects of ventral root section did not occur via the spinal cord. Combined lesions of sciatic nerve and dorsal root also failed to abolish the appearance of rings. Therefore, the $\mathrm{p} 75$ glial response within ipsilateral DRGs requires damage of motor nerve fibers.

Two possible explanations to account for this phenomenon are as follows. (1) Positive signals may be generated from Schwann cells around degenerating motor axons, which spread to myelinated afferent fibers within the same nerve trunk and signal back to cell bodies in the DRGs. The cell bodies would then release secondary signals to induce glial proliferation (Wen et al., 1994) and/or upregulation of p75. (2) Negative signals may normally be produced in target muscles that suppress the expression of $\mathrm{p} 75$ by glia around afferent neurons projecting to the same muscles. These would be downregulated by motor nerve lesions and/or eliminated by peripheral sensory axotomy. The evidence of altered trophic factor synthesis in muscle after peripheral nerve lesions is strong. Sciatic nerve transection induces a significant reduction of mRNA ${ }^{\mathrm{NT3}}$ and $\mathrm{mRNA}^{\mathrm{NT} 4}$ in affected muscles (Funakoshi et al., 1993, 1995). This response can be mimicked by neuromuscular blockade using $\alpha$-bungarotoxin, indicating that the response is mediated by motor nerve activity (Funakoshi et al., 1995). Because large-diameter neurons containing trkC and NT3-ir project to muscles and are dependent on NT3 for survival (Farinas et al., 1994; Klein et al., 1994; Zhou and Rush, 1995a), it is possible that muscle-derived NT3 (and/or NT4) represses the secretion of diffusible factors by sensory neurons that upregulate glial p75 expression in adult animals. Thus, large sensory neurons deprived of NT3, either by muscle denervation (downregulation) or by peripheral axotomy, would trigger the glial response.

\section{Is the increased glial expression of p75 involved in noradrenergic sprouting?}

This study has shown $\mathrm{TH}$-ir axons associated with $\mathrm{p} 75$-ir glial cells. Although sympathetic neurons normally express p75 and their responsiveness to NGF most likely involves this receptor, p75 binds all four neurotrophins with similar affinity (RodriguezTébar et al., 1990, 1992; Barbacid, 1993), and its presence does not necessarily correlate with a specific requirement for NGF (Barbacid, 1993; Zhou et al., 1993). Upregulation of glial p75 after nerve trauma, therefore, may provide an ideal microenvironment for sprouting in response to neurotrophins secreted from glial cells (Johnson et al., 1988). Recent ultrastructure studies indicate that TH-ir sprouts after sciatic lesions do not synapse with sensory neurons but form onion structures closely related to their glia (Devor et al., 1995). Furthermore, $\mathrm{mRNA}^{\mathrm{NGF}}$ is significantly increased in DRGs after sciatic lesions (Sebert and Shooter, 1993) despite a reduced supply from the periphery (Heumann et al., 1987) caused by decreased synthesis of neuronal NGF receptors 
(Verge et al., 1989; Raivich et al., 1991). It is well established that other neurotrophins are expressed in proliferating satellite cells of damaged nerves (Wen et al., 1994), but whether their synthesis is also increased has yet to be investigated (Heumann et al., 1987; Meyer et al., 1992).

Sympathetic neurons express both $t r k A$ and $t r k C$, the putative high-affinity receptors for NGF and NT3, respectively, and are responsive to both factors during development in vitro (Hohn et al., 1990) and in vivo (Ernfors et al., 1994; Zhou and Rush, 1995b). Most noradrenergic rings are associated with large primary afferent neurons (McLachlan et al., 1993) that contain, and are sensitive to, NT3 (Farinas et al., 1994; Klein et al., 1994; Zhou and Rush, 1995b). Thus, it is possible that noradrenergic sprouting in rat DRGs occurs as a result of the increased synthesis of both p75 and NGF and/or NT3 by satellite cells surrounding these largediameter neurons. Because adult glia do not synthesize highaffinity neurotrophin receptors (Offenhauser et al., 1995), glial p75 most likely functions as a presenting molecule (Barbacid, 1993) for newly synthesized NT3 and/or NGF to trigger sprouting of sympathetic nerve terminals. The close association of $\mathrm{TH}$-ir fibers with p75-ir glia supports this hypothesis, although the possibility that novel diffusible factors derived from proliferating glia are responsible cannot be eliminated. The use of neutralizing antibodies to NGF and NT3, or the p75 null mutant mouse, could be valuable in determining which molecules are directly involved in triggering noradrenergic sprouting.

\section{REFERENCES}

Abrahamson IK, Bridges D, Rush RA (1987) Transport of endogenous nerve growth factor in the proximal stump of sectioned nerves. J Neurocytol 16:417-422.

Barbacid M (1993) Nerve growth factor: a tale of two receptors. Oncogene 8:2033-2042.

Bonica JJ (1990) Causalgia and other reflex sympathetic dystrophies. In: The management of pain (Bonica JJ, ed), pp 220-243. Philadelphia: Lea \& Febiger.

Campenot RB (1987) Local control of neurite sprouting in cultured sympathetic neurons by nerve growth factor. Brain Res 465:293-301.

Davis BM, Albers KM, Seroogy KB, Katz DM (1994) Overexpression of nerve growth factor in transgenic mice induces novel sympathetic projections to primary sensory neurons. J Comp Neurol 349:464-474.

Devor M, Govrin-Lippmann R, Frank I, Raper P (1985) Proliferation of primary sensory neurons in adult rat dorsal root ganglia and the kinetics of retrograde cell loss after sciatic nerve section. Somatosens Res $3: 139-167$.

Devor M, Shinder V, Govrin-Lippman R (1995) Sympathetic sprouting in axotomized rat DRG: ultrastructure. Soc Neurosci Abstr 21:894.

Diamond J, Foerster A, Holmes M, Coughlin M (1992a) Sensory nerves in adult rats regenerate and restore sensory function to the skin independently of endogenous NGF. J Neurosci 12:1467-1476.

Diamond J, Holmes M, Coughlin M (1992b) Endogenous NGF and nerve impulses regulate the collateral sprouting of sensory axons in the skin of the adult rat. J Neurosci 12:1454-1466.

Donaldson LF, McQueen DS, Seckl JR (1995) Neuropeptide gene expression and capsaicin-sensitive primary afferents: maintenance and spread of adjuvant arthritis in the rat. $\mathbf{J}$ Physiol (Lond) 486:473-482.

Dropp JJ, Sodetz FJ (1971) Autoradiographic study of neurons and neuroglia in autonomic ganglia of behaviourly stressed rats. Brain Res 33:419-430.

Edwards RH, Rutter WJ, Hanahan D (1989) Directed expression of NGF to pancreatic $\beta$ cells in transgenic mice leads to selective hyperinnervation of the islets. Cell 58:161-170.

Enfors P, Lee K-F, Kucera J, Jaenisch R (1994) Lack of neurotrophin-3 leads to deficiencies in the peripheral nervous system and loss of limb proprioceptive afferents. Cell 77:503-512.

Farinas I, Jones KR, Bachus C, Wang X-Y, Reichardt LF (1994) Severe sensory and sympathetic deficits in mice lacking neurotrophin-3. Nature 369:658-661.
Federoff HJ, Geschwind MD, Geller AI, Kessler JA (1992) Expression of nerve growth factor in vivo from a defective herpes simplex virus 1 vector prevents effects of axotomy on sympathetic ganglia. Proc Natl Acad Sci IJSA 89:1636-1640.

Funakoshi H, Frisén J, Barbany G, Timmusk T, Zachrisson O, Verge VMK, Persson H (1993) Differential expression of mRNAs for neurotrophins and their receptors after axotomy of the sciatic nerve. J Cell Biol 123:455-465.

Funakoshi H, Belluardo N, Arenas E, Yamamoto Y, Casabona A, Persson H, Ibanez CF (1995) Muscle-derived neurotrophin-4 as an activitydependent trophic signal for adult motor neurons. Science 268: 1495-1499.

Greeson DM, Moix L, Meier M, Armstrong DM, Wiley RG (1992) A continuing signal maintains NGF receptor expression in hypoglossal motor neurons after crush injury. Brain Res 594:351-355.

Henry MA, Westrum LE, Bothwell M, Johnson LR (1993) Nerve growth factor receptor (p75)-immunoreactivity in the normal adult feline trigeminal system and following retrogasserian rhizotomy. J Comp Neurol 335:425-436

Heumann R, Korsching S, Bandtlow C, Thoenen H (1987) Changes of nerve growth factor synthesis in non-neuronal cells in response to sciatic nerve transection. J Cell Biol 104:1623-1631.

Hohn A, Leibrock J, Bailey K, Barde Y-A (1990) Identification and characterization of a novel member of the nerve growth factor/brain derived neurotrophic factor family. Nature 344:339-341

Hökfelt T, Zhang X, Wiesenfeld-Hallin Z (1994) Messenger plasticity in primary sensory neurons following axotomy and its functional implications. Trends Neurosci 17:22-30.

Jänig W, Schmidt RF (1992) Refex sympathetic dystrophy: pathophysiological mechanisms and clinical implications (Jänig W, Schmidt RF, eds). New York: VCH.

Johnson $I_{\Gamma}$ EM, Taniuchi M, DiStefano PS (1988) Expression and possible function of nerve growth factor receptors on Schwann cells. Trends Neurosci 11:299-304.

Klein R, Silos-Santiago I, Smeyne RJ, Lira SA, Brambilla R, Bryant S, Zhang L, Snider WD, Barbacid M (1994) Disruption of the neurotrophin-3 receptor gene trkC eliminates Ia muscle afferents and results in abnormal movements. Nature 368:249-251.

Koliatsos VE, Crawford TO, Price DL (1991) Axotomy induces nerve growth factor receptor immunoreactivity in spinal motor neurons. Brain Res 549:297-304

Kolston J, Lisney SJW, Mulholland MNC, Passant CD (1991) Transneuronal cffects triggcred by saphenous nerve injury on one side of a rat are restricted to neurones of the contralateral, homologous nerve. Neurosci Lett 130:187-189.

Lindsay RM, Shooter EM, Radeke MJ, Misko TP, Dechant G, Thoenen H, Lindholm D (1990) Nerve growth factor regulates expression of the nerve growth factor receptor gene in adult sensory neurons. Eur $\mathbf{J}$ Neurosci 2:389-396.

Lu X, Richardson PM (1991) Inflammation near the nerve cell body enhances axonal regeneration. J Neurosci 11:972-978.

McLachlan EM, Jänig W, Devor M, Michaelis M (1993) Peripheral nerve injury triggers noradrenergic sprouting within dorsal root ganglia. Nature 363:543 545 .

Meyer M, Matsuoka I, Wetmore C, Olson L, Thoenen H (1992) Enhanced synthesis of brain-derived neurotrophic factor in the lesioned peripheral nerve: different mechanisms are responsible for the regulation of BDNF and NGF mRNA. J Cell BIol 119:45-54.

Offenhauser N, Bohmmatthaei R, Tsoulfas P, Parada L, Meyer M (1995) Developmental regulation of full-length trke in the rat sciatic nerve. Eur J Neurosci 7:917-925.

Pubols LM, Fogleson ME (1988) Acute and chronic effects the neurolytic agent ricin on dorsal root ganglia, spinal cord and nerves. J Comp Neurol 275:271-281.

Raivich G, Hellweg R, Kreutzberg GW (1991) NGF receptor-mediated reduction in axonal NGF uptake and retrograde transport following sciatic nerve injury and during regeneration. Neuron 7:151-164.

Rende M, Provenzano C, Tonali P (1993) Modulation of low-affuity nerve growth factor receptor in injured adult rat spinal cord motoneurons. J Comp Neurol 338:560-574.

Rich KM, Johnson EMJ (1985) Ventral rhizotomy enhances regeneration of uninjured sensory neurons. Brain Res 335:182-187.

Rich KM, Yip HK, Osborne PA, Schmidt RE, Johnson EM (1984) Role of nerve growth factor in the adult dorsal root ganglia neuron and its response to injury. J Comp Neurol 230:110-118. 
Rich KM, Luszczynsky TR, Osborne PA, Schmidt RE, Johnson EM (1987) Nerve growth factor protects adult sensory neurons from cell death and atrophy caused by injury. J Neurocytol 16:261-268.

Richardson PM, Issa VMK (1984) Peripheral injury enhances central regeneration of primary sensory neurones. Nature 309:791-793.

Richardson PM, Verge VMK (1986) The induction of a regenerative propensity in sensory neurons following peripheral axonal injury. J Neurocytol 15:585-594.

Rodriguez-Tébar A, Dechant G, Barde Y-A (1990) Binding of brainderived neurotrophic factor to the nerve growth factor receptor. Neuron 4:487-492.

Rodriguez-Tebar A, Dechant G, Gotz R, Barde YA (1992) Binding of neurotrophin-3 to its neuronal receptors and interactions with nerve growth factor and brain-derived neurotrophic factor. EMBO J 11:917-922.

Rotshenker S (1988) Multiple modes and sites for the induction of axonal growth. Trends Neurosci 11:363-366.

Rush RA (1984) Immunohistochemical localisation of endogenous nerve growth factor. Nature 312:364-367.

Schwyn RC (1967) An autoradiographic study of satellite cells in autonomic ganglia. Am J Anat 121:727-740.

Sebert ME, Shooter EM (1993) Expression of mRNA for neurotrophic factors and their receptors in the rat dorsal root ganglion and sciatic nerve following nerve injury. J Neurosci Res 36:357-367.

Taniuchi M, Clark HB, Johnson EM (1986) Induction of nerve growth factor receptor in Schwann cells after axotomy. Proc Natl Acad Sci USA 83:4094-4098.
Verge VM, Riopelle RJ, Richardson PM (1989) Nerve growth factor receptors on normal and injured sensory neurons. J Neurosci 9:914-922.

Verge VM, Merlio JP, Grondin J, Ernfors P, Persson H, Riopelle RJ, Hokfelt T, Richardson PM (1992) Colocalization of NGF binding sites, trk mRNA, and low-affinity NGF receptor mRNA in primary sensory neurons: responses to injury and infusion of NGF. J Neurosci 12:4011-4022.

Wen JYM, Morshead CM, Van der Kooy D (1994) Satellite cell proliferation in the adult rat trigeminal ganglion results from the release of a mitogenic protein from explanted sensory neurons. J Cell Biol 124:1005-1015.

Woolf CJ, Shortland P, Coggeshall RE (1992) Peripheral nerve injury triggers central sprouting of myelinated afferents. Nature 355:75-78.

Zhou X-F, Rush RA (1995a) Peripheral projections of rat primary sensory neurons immunoreactive for neurotrophin 3. J Comp Neurol 363:69-77.

Zhou X-F, Rush RA (1995b) Sympathetic neurons in neonatal rats require endogenous neurotrophin-3 for survival. $J$ Neurosci 15:6521-6530.

Zhou X-F, Rush RA (1996) Endogenous NGF is required for regulation of the low affinity NGF receptor in sympathetic but not sensory ganglia. $\mathrm{J}$ Comp Neurol, in press.

Zhou X-F, Gai W-P, Rush RA (1993) CGRP immunoreactive neurons in rat dorsal root ganglia do not all contain low-affinity NGF receptor immunoreactivity. Brain Res 612:322-325. 